\title{
Determination of the Presence or Absence of Sulfur Materials in Drywall Using Direct Analysis in Real Time in Conjunction with an Accurate-Mass Time-of-Flight Mass Spectrometer
}

\author{
Matthew E. Curtis, ${ }^{\text {a }}$ Patrick R. Jones, ${ }^{\text {a }}$ O. David Sparkman, ${ }^{\text {a }}$ and \\ Robert B. Cody ${ }^{\mathrm{b}}$ \\ ${ }^{a}$ Pacific Mass Spectrometry Facility, Department of Chemistry, College of the Pacific, University of the \\ Pacific, Stockton, California, USA \\ b JEOL USA, Inc., Peabody, Massachusetts, USA
}

Based on the concern about the presence of sulfur materials being in drywall (wallboard), a quick and reliable test to confirm the presence or absence of these materials using direct analysis in real time (DART) mass spectrometry in conjunction with an accurate-mass time-of-flight (TOF) mass spectrometer has been developed and is described here. (J Am Soc Mass Spectrom 2009, 20, 2082-2086) (c) 2009 American Society for Mass Spectrometry

I n recent weeks, there have been a number of reports in the legitimate press about problems homeowners have been having with what is believed to be emission from drywall that was reported to be manufactured in China [1-7]. Various tests have been performed, such as the one conducted by Unified Engineering, Inc., Aurora, IL, for the Florida Department of Health, Division of Environmental Health, and reported on March 17, 2009. All of these tests have been less than conclusive. The Unified Engineering report did state that hydrogen sulfide, carbonyl sulfide, and carbon disulfide were detected at levels between 100 and 1 ppm with a GC-AED (gas chromatograph-atomic emission detector) headspace analysis technique applied to samples of "bulk drywall material with the outside papers removed" after a 24-h exposure to 95\% humidity followed by setting a sample in a septum vial containing dry nitrogen for another $24 \mathrm{~h}$. It was also reported by Unified Engineering that there was "a distinct sulfur odor from all three Chinese drywall samples."

The Pacific Mass Spectrometry Facility was contacted by an East Coast developer looking for a quick, simple, and inexpensive test that could conclusively determine if there was a potential problem based on the presence of sulfur or sulfur-containing compounds. The concern was based on analytical tests that had been conducted on reported odors observed by homeowners and investigators, and the observation of copper materials that had turned black in the homes. These tests

Address reprint requests to Dr. O. D. Sparkman, Department of Chemistry, Pacific Mass Spectrometry Facility, University of the Pacific, 3601 Pacific Ave., Stockton, CA 95211, USA. E-mail: osparkman@pacific.edu supported that the probable source of problems was some sulfur-containing material in the drywall material.

The Pacific Mass Spectrometry Facility was provided with drywall samples labeled "American Drywall" and "China Drywall". Both samples were identified by labels written on one of the two paper coverings with a green felt-tip pen. The "American Drywall" sample measured $18 \mathrm{~cm} \times 11.5 \mathrm{~cm} \times 1.7 \mathrm{~cm}$ (slightly greater than 5/8 in. thick). The "China Drywall" sample measured $13.3 \mathrm{~cm} \times 11 \mathrm{~cm} \times 1.4 \mathrm{~cm}$ (slightly greater than $1 / 2$ in. thick. The contractor sent the 5/8-in. American Drywall sample because no 5/8-in. drywall had been imported from China. After removing some of the material between the paper coverings comprising the outside covers of the drywall, it was observed that the material from the "China Drywall" sample was a grayishbrown color and had a much coarser grain than the "American Drywall" material. The "American Drywall" material was almost a pure white in color. Samples of the material removed from between the surface coverings were placed in 16-mL glass vials with Teflonlined caps and allowed to stand tightly sealed overnight at room temperature. There was no special effort to change the air in the vials to an inert gas. The next day, when each vial was opened, the "China Drywall" sample emitted a distinct sulfur odor that could best be described as that of sulfur dioxide. This odor was not present from the vial containing the "American Drywall" material.

Direct analysis in real time (DART), in conjunction with accurate-mass mass spectrometry, has been used for the determination of many analytes in complex matrices without any extraction or other sample preparation. Combining the speed of sampling by DART 
with the accurate-mass measurement of a TOF mass spectrometer had the potential of meeting the needs for a simple yet unambiguous test to confirm the presence or absence of volatile sulfur-containing materials in drywall.

The DART technology allows for samples to be held in the open-air space between the DART ion source and the entrance to an atmospheric pressure ionization interface of a mass spectrometer. Analytes undergo desorption/ionization in this position and the ions are drawn into the mass spectrometer for separation according to their mass-to-charge ratio $(\mathrm{m} / \mathrm{z})$ values. The DART technology was introduced in 2005 in a presentation at the American Society for Mass Spectrometry's 17th Sanibel Conference, Mass Spectrometry in Forensics and Counter Terrorism, held January 28-February 1. This introduction was followed later in February of that same year by a product release from JEOL USA, Inc. in Peabody, MA, where the availability of the DART open-air desorption/ionization system in conjunction with their AccuTOF mass spectrometer was announced. The developers of this patented technology, Robert B. Cody (JEOL USA) and James Laramèe (EAI Corp.), along with H. Dupont Durst (U.S. Army Edgewood Chemical Biological Center) published an article describing the basics of how DART worked and showed a number of practical applications [8]. This article appeared on-line on March 12, 2005.

Since that time, DART has shown itself to be a very effective tool in the analysis of many different types of samples in many different matrices without any sample preparation [9-14]. The Pacific Mass Spectrometry Facility has demonstrated the detection of melamine in pet food using a sample taken to the mass spectrometer directly from the container without any sample preparation [15].

DART functions by forming helium metastable atoms in a heated stream of He gas subjected to an electrical discharge. The DART ion source removes any ions that are formed, and delivers, to the space between the source and the entrance to the atmospheric pressure interface of the mass spectrometer, a He gas stream that is rich in He metastable. This He metastable rich gas stream can be heated to aid in the desorption of samples on surfaces. Schematic representations of the DART ion source and its orientation to the mass spectrometer can be found in references $[8,15]$. As was pointed out in the original DART publication [8], the mechanism of ionization is not clear. The DART ion source can produce positive molecular ions (maybe through Penning ionization), protonated molecules, thought possible by proton transfer from protonated water clusters or by protonated matrix components, positive-charge adduct ions such as ammoniated ions and negative-charge ions (both molecular and even electron) through electron capture ionization and dissociative electron capture ionization. Details of these mechanisms are beyond the scope of this Applications Note.
The first attempts at analyzing for substances that might be present in the drywall samples were made at several different temperatures, using positive-ion detection. The resulting mass spectra showed no differences between the "China Drywall" and the "American Drywall" samples. However, when the samples were put in the DART gas stream at $250{ }^{\circ} \mathrm{C}$, the "China Drywall" sample omitted a noticeable odor, which was also described as seeming to suggest sulfur dioxide. No odor was observed with the "American Drywall" sample. After having failed with positive-ion analysis in the differentiation between the two samples, negative-ion detection was attempted. This proved very effective, and an unambiguous difference in the two samples was observed.

\section{Experimental}

Both the "American Drywall" and the "China Drywall" samples were scored with a clean blade and split open to expose gypsum-based material in the interior of the drywall. A metal spatula was pressed into the gypsum to release small chunks, which were placed into a 16-mL screw-capped glass vial to obtain the samples.

The chunks were placed directly into the sample gap of the DART (IonSense, Inc., Saugus, MA, USA) using metal tweezers, rapidly moving the sample in and out of the helium stream so as not to block the ions from entering the mass spectrometer through orifice 1 . The DART orientation was optimized to maximize the $\mathrm{O}_{2}^{-}$ ion, $m / z 31.9898$, and the He gas temperature was set to $250{ }^{\circ} \mathrm{C}$ with a gas-flow setting of 9.42 (arbitrary units), a grid voltage of $-500 \mathrm{~V}$, and a needle voltage set to 2750 V. The AccuTOF (JEOL USA, Inc., Peabody, MA, USA) mass spectrometer was set to acquire negative-ion spectra with a peaks voltage and orifice 1 of $550 \mathrm{~V}$ and $-20 \mathrm{~V}$, respectively. The spectral acquisition range was $m / z 55$ to 1000 at a rate of 1 spectrum $\mathrm{s}^{-1}$. Spectra were acquired for $\sim 1 \mathrm{~min}$ for both the "American Drywall"

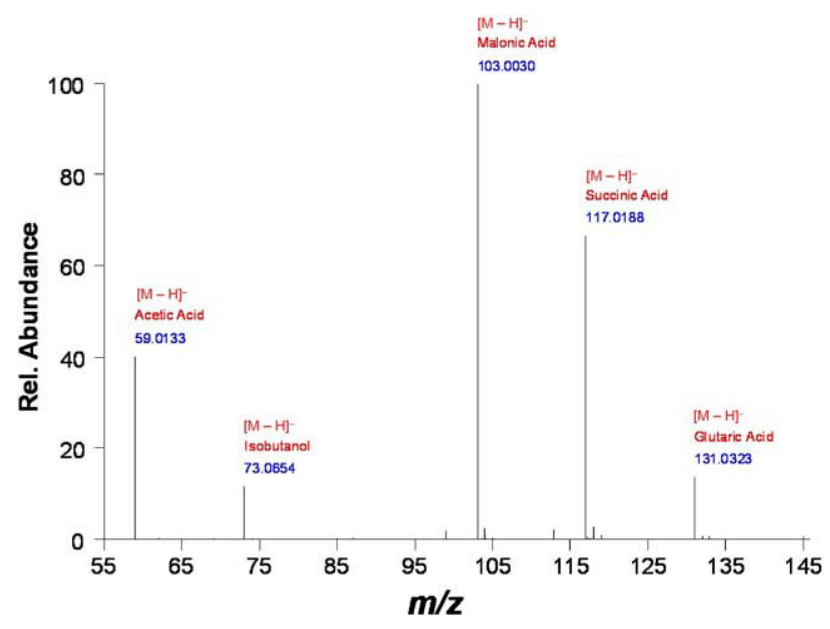

Figure 1. Mass spectrum of the $m / z$-scale calibration solution obtained using the DART AccuTOF mass spectrometer in the Pacific Laboratory. 
and the "China Drywall" samples. The AccuTOF was operated at its maximum resolving power of 7000 (FWHM).

Calibration spectra were collected within each data file at the end of the analysis to provide the necessary reference ions for an accurate-mass assignment. A calibration solution was formulated using acetic acid, isobutanol, malonic acid, succinic acid, and glutaric acid dissolved in methanol, with an approximate concentration of $500 \mathrm{ng} \mu \mathrm{L}^{-1}$ per compound. Spectral data were acquired continuously. Data acquired when no sample was in the DART interface just before sample spectra being acquired were used as a background signal.

Each data file contained spectra of the calibration solution, the "American Drywall", and the "China Drywall" as well as the background spectral data. After the data acquisition was completed, accurate-mass values were assigned for the major peaks in the mass spectrum by TSSPro 3.0 (Shrader Labs Inc., Detroit, MI, USA). Four to five spectra representing each sample were averaged before the assignment of the accuratemass values. An averaged background spectrum using four to five spectra taken when no sample was present in the interface was subtracted from the average sample spectrum before accurate-mass assignment. Once the accurate-mass values were assigned, the elemental composition of the ion was established and a comparison was made of the intensities of the observed isotope peaks and the calculated intensities for the assigned elemental composition using Elemental Compositions and Isotope Ratio Calc, a program within MS Tools (ChemSW Inc., Fairfield, CA, USA). The Element limits used for the elemental composition calculator were: $\mathrm{C} 0 / 20, \mathrm{H} 0 / 100, \mathrm{O} 0 / 5, \mathrm{~N} 0 / 5$, S 0/5. The combination of accurate mass and the match of relative isotopic intensities served to validate the elemental compositions.

Several analyses of the samples were made during the same day and were repeated over several subsequent days to assure that results were reproducible. No attempt was made to quantitate any observed substance. In addition, samples of the "American Drywall"

\section{Intensity of $\mathrm{m} / \mathrm{z} 95.9300$ is 325,275 counts}

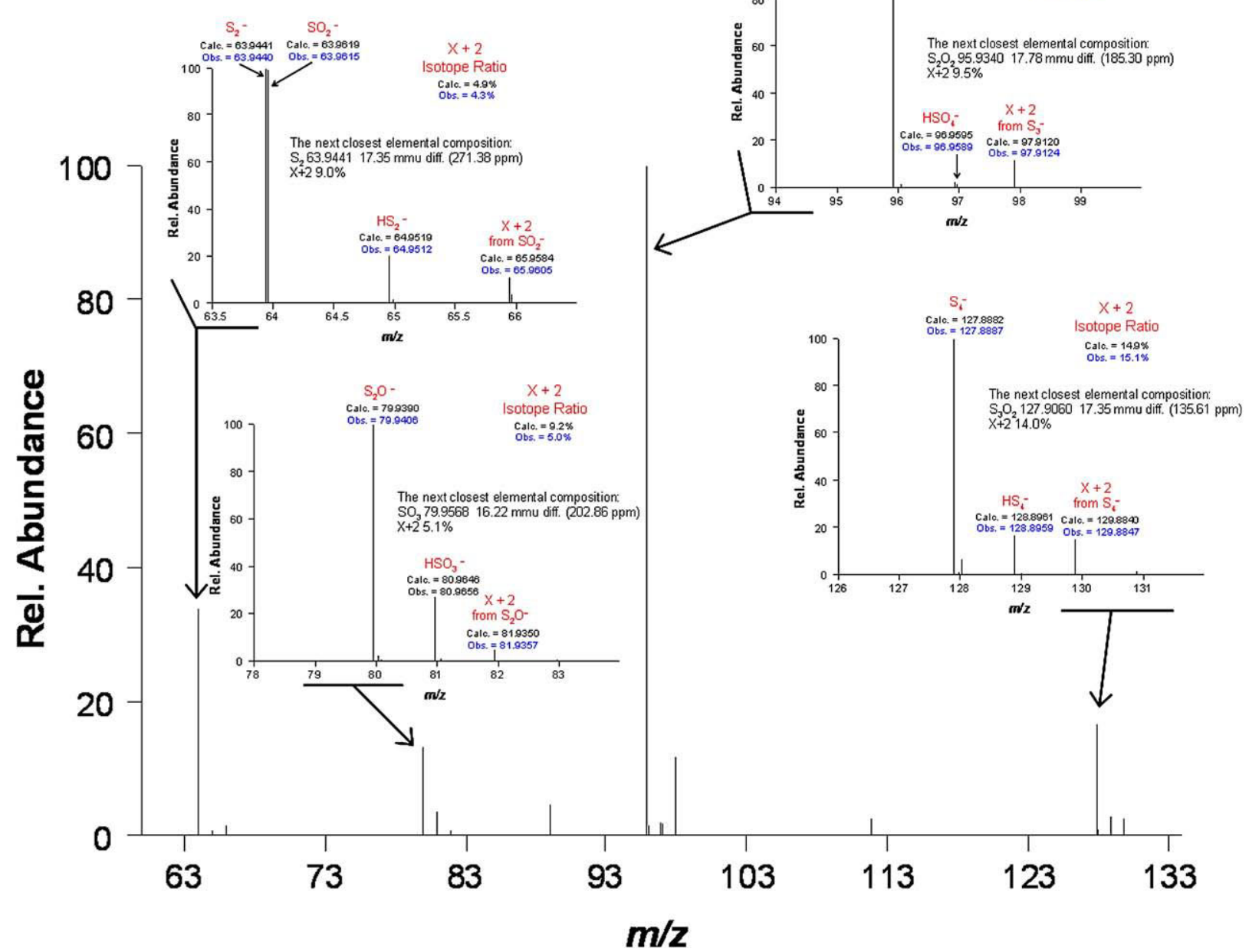

Figure 2. Mass spectrum obtained using negative-ion detection with the DART AccuTOF mass spectrometer of the sample labeled "China Drywall." 


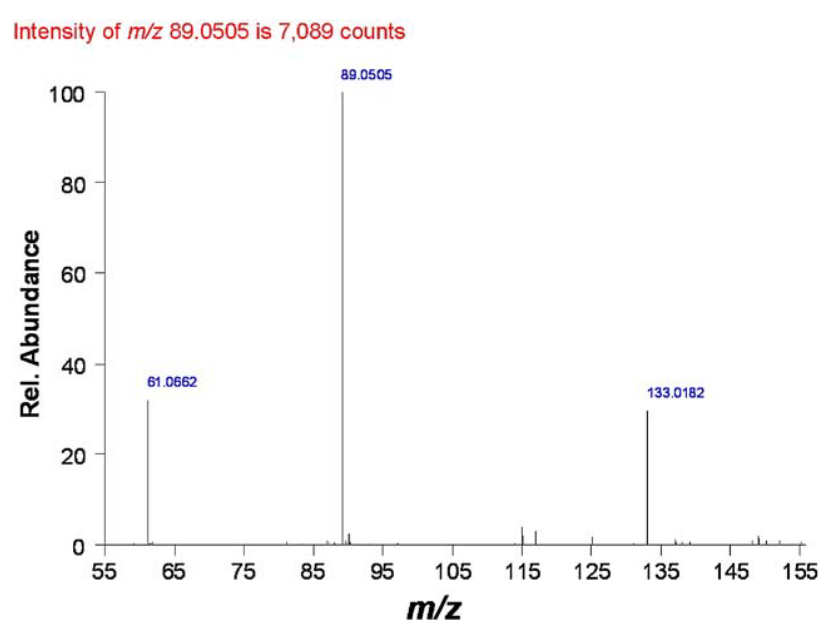

Figure 3. Mass spectrum obtained using negative-ion detection with the DART AccuTOF mass spectrometer of the sample labeled "American Drywall."

and the "China Drywall" were sent to the JEOL Application Laboratory in Peabody, MA, where they were analyzed using a different DART AccuTOF instrument by a different analyst. The only difference in the JEOL and the Pacific analyses was that polyethylene glycol (PEG) was used as the $m / z$-scale calibrant for the JEOL analyses.

\section{Results and Conclusions}

None of the mass spectra of samples analyzed under the negative-ion detection conditions described above ex- hibited any ion current above $\mathrm{m} / \mathrm{z} 150$ other than that which could be attributed to very low abundance ions that are due to the normal operating background of the instrument. Due to the use of negative-ion detection, the background was very clean. Figure 1 is a normalized mass spectrum showing peaks representing the ions used for the calibration of the $\mathrm{m} / \mathrm{z}$ scale in the Pacific Laboratory.

The mass spectrum shown in Figure 2 for the "China Drywall" sample exhibited a base peak, which represented a signal strength $\sim 46$ times the intensity of the base peak in the mass spectrum obtained from the "American Drywall" sample (325,275 counts versus 7089 counts), Figure 3. As can be seen from Figure 2, the mass spectrum obtained from the "China Drywall" sample exhibits four sets of mass spectral peaks that have a clear $\mathrm{X}+2$ isotope pattern, which can be attributed to sulfur compounds based on the relative intensity of the $X+2$ peak to the $X$ peak. In all four cases, except for the peak at nominal $\mathrm{m} / z$ 80, the $X+2$ values are well within the $\pm 10 \%$ window of calculated values versus experimental values.

The base peak in the mass spectrum in Figure 2 is at nominal $\mathrm{m} / \mathrm{z}$ 96. Figure 4 is a reconstructed ion current (RIC) profile for the accurate mass value assigned to the ion represented by this peak. The profile covers the period during which the "China Drywall", the calibrant, and the "American Drywall" were in the DART interface, respectively. This RIC profile clearly indicated that ions with nominal $\mathrm{m} / \mathrm{z} 96$ are produced by substances in the "China Drywall" and are not produced from the "American Drywall".

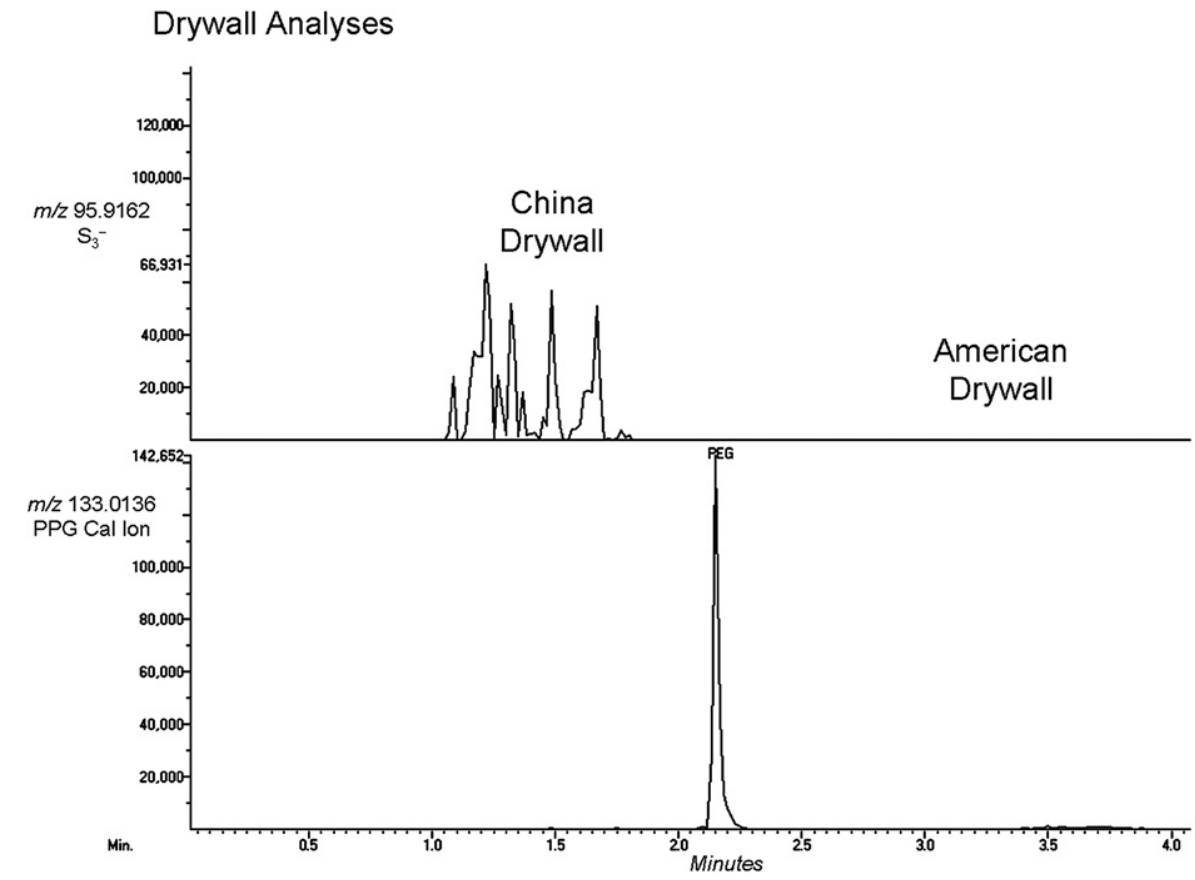

Figure 4. (Top) reconstructed ion current (RIC) profile for $m / z$ 95.9162, the base peak in the mass spectra obtained for the "China Drywall" and "American Drywall" samples. (Bottom) RIC profile for a calibration ion used in the analyses of drywall samples performed by JEOL Application Laboratory. 
The peak at nominal $\mathrm{m} / \mathrm{z} 64$ is a resolved doublet representing $\mathrm{S}_{2}^{-}(63.9440 \mathrm{Da})$ and $\mathrm{SO}_{2}^{-}(63.9615 \mathrm{Da})$ ions; a respective difference between measured and calculated masses of 0.1 and $0 \mathrm{mmu}$ ). The peak at nominal $\mathrm{m} / \mathrm{z} 65$ not only represents the $\mathrm{S}_{2}^{-}$ion where one of the $\mathrm{S}$ atoms is ${ }^{33} \mathrm{~S}$, and the $\mathrm{SO}_{2}^{-}$ion where the $\mathrm{S}$ is ${ }^{34} \mathrm{~S}$, or one of the $\mathrm{O}$ atoms is ${ }^{17} \mathrm{O}$; but based on the measured mass, it mainly represents the $\mathrm{HS}_{2}^{-}$ion. This is supported by the doublet at nominal $m / z 66$.

The peak at nominal $\mathrm{m} / \mathrm{z} 80$ is an unresolved doublet representing $\mathrm{SO}_{3}^{-}$and $\mathrm{S}_{2} \mathrm{O}^{-}$. Even though the difference in the calculated mass of the $\mathrm{S}_{2} \mathrm{O}^{-}$ion and the measured value for the peaks supports this elemental composition, the $\mathrm{X}+2$ intensity supports the $\mathrm{SO}_{3}^{-}$composition (calculated relative intensity of $9.2 \%$ compared with an observed value of $5.0 \%$ ).

Both the agreement between the calculated and measured mass for the $S_{3}^{-}$(zero difference) and the agreement between the calculated and observed values for the $X+2$ intensity $(11.9 \%$ observed versus $13.5 \%$ calculated) for the peak at nominal $\mathrm{m} / \mathrm{z} 96$ support this composition. It is also seen from the resolved doublet associated with the peak with nominal $\mathrm{m} / \mathrm{z} 97$ that $\mathrm{HSO}_{4}^{-}$is formed. The calculated and measured masses associated with series of peaks with nominal $m / z 128$, 129 , and 130 support elemental compositions of $S_{4}^{-}$and $\mathrm{HS}_{4}^{-}$.

Based on the mass spectra, clearly some substance in the "China Drywall" produces ions that contain atoms of sulfur. Based on the RIC profile for the ion with nominal $\mathrm{m} / \mathrm{z} 96$ and the mass spectra, clearly these ions are not produced by the "American Drywall" when subjected to the same analytical conditions using the DART AccuTOF mass spectrometer. This mass spectrometric method can be used to confirm whether a drywall sample contains substances that will emit ions containing sulfur.

\section{References}

1. Corkery, M. Homeowner Problems with Chinese-Made Drywall Spread; The Wall Street Journal: New York, April 17, 2009, Real Estate, Homeowner Problems with Chinese-Made Drywall Spread-WSJ.com.

2. Skoloff, B. Chinese Drywall Poses Potential Risks; AP IMPACT: Saturday, April 11, 2009 11:30 AM EDT.

3. Skoloff, B. Florida to test air in homes with Chinese drywall; USA Today: http://www.usatodayeconomy/housing/2009-04-17-chinese-drywall_ N.htm.

4. Schmit, J. Drywall from China blamed for problems in homes; USA Today: Updated 3/17/2009 3:20 PM.

5. Norfolk votes to ban Chinese drywall; USA Today: Posted 5/19/2009 6:45 PM ET.

6. Thorner, J. Florida builders brace for suits over odor-emitting Chinese drywall; St. Peterburg Times: Saturday March 21, 2009, http://www. tampabay.com/news/business/realestate/article985827.ece.

7. Bradley, L. U.S. Hearings Open Today on Chinese Drywall: Another Import Made with Reckless Abandon; USA Today: May 21, 2009 5:00 AM.

8. Cody, R. B.; Laramèe, J. A.; DuPont Durst, H. Versatile New Ion Source for the Analysis of Materials in Open Air under Ambient Conditions. Anal. Chem. 2005, 77(8), 2297-2302.

9. Haefliger, O. P.; Jeckelmann, N. Direct Mass Spectrometric Analysis of Flavors and Fragrances in Real Applications Using DART. Rapid Commun. Mass Spectrom. 2007, 21, 1361-1366.

10. Kpegba, K.; Spadaro, T.; Cody, R. B.; Nesnas, N.; Olson, J. A. Analysis of Self-Assembled Monolayers on Gold Surfaces Using Direct Analysis in Real Time Mass Spectrometry. Anal. Chem. 2007, 79, 5479-5483.

11. Madhusudanan, K. P.; Banerjee, S.; Khanuja, S. P. S.; Chattopadhyay, S. K. Analysis of Hairy Root Culture of Rauvolfia serpentina Using Direct Analysis in Real Time Mass Spectrometric Technique. Biomed. Chromatogr. 2008, 22, 596-600.

12. Morlock, G.; Ueda, Y. New Coupling of Planar Chromatography with Direct Analysis in Real Time Mass Spectrometry. J. Chromatogr. A 2007, $1143,243-251$.

13. Petucci, C.; Diffendal, J.; Kaufman, D.; Mekonnen, B.; Terefenko, G.; Musselman, B. Direct Analysis in Real Time for Reaction Monitoring in Drug Discovery. Anal. Chem. 2007, 79, 5064-5070.

14. Grange, A. H.; Sovocool, G. W. Automated Determination of Precursor Ion, Product Ion, and Neutral Loss Compositions and Deconvolution of Composite Mass Spectra Using Ion Correlation Based on Exact Masses and Relative Isotopic Abundances. Rapid Commun. Mass Spectrom. 2008, 22, 2375-2390.

15. Vail, T. M.; Sparkman, O. D.; Jones, P. R. Rapid and Unambiguous Identification of Melamine in Contaminated Pet Food Based on Mass Spectrometry with Four Degrees of Confirmation. J. Anal. Toxicol. 2007, 31, 304-312. 